\title{
Green Taxation and Total Factor Productivity
}

\author{
Zihan Hu \\ Department of Accounting, Jinan University, Guangzhou, China \\ Email: h2436541775@163.com
}

How to cite this paper: Hu, Z.H. (2019) Green Taxation and Total Factor Productivity. Modern Economy, 10, 698-706. https://doi.org/10.4236/me.2019.103047

Received: February 18, 2019

Accepted: March 12, 2019

Published: March 15, 2019

Copyright $\odot 2019$ by author(s) and Scientific Research Publishing Inc. This work is licensed under the Creative Commons Attribution International License (CC BY 4.0).

http://creativecommons.org/licenses/by/4.0/

\begin{abstract}
As one of the means of the government to protect the environment, green taxation can effectively control pollution emissions and alleviate environmental pressures. However, there is considerable controversy about whether the implementation of green taxation has a favorable impact on economic growth. Therefore, this paper systematically summarizes the impact of green tax collection on enterprises and the factors affecting total factor productivity, and further analyzes whether green tax collection has an impact on corporate total factor productivity. Finally, the corresponding policy recommendations are put forward, from the formulation of reasonable green tax intensity, the development of differentiated industry green tax intensity and the adoption of flexible green tax forms, etc.
\end{abstract}

\section{Keywords}

Green Taxation, Total Factor Productivity, Manufacturing

\section{Introduction}

\subsection{Background}

The 19th National Congress report puts forward the concept of green development, which not only shows China's emphasis on ecological environmental protection, but also reflects the current severe situation of environmental pollution and waste of resources. Therefore, the government has adopted a series of green tax collection measures.

Green tax collection will inevitably have an impact on the production and operation of enterprises. The most obvious impact is to increase the expenditure of enterprises to discharge various pollutants, which will have an impact on the production efficiency of enterprises; higher than the cost of active governance, it will increase the enthusiasm of enterprises to actively reduce pollution and reduce emissions. Enterprises will reduce the environmental management costs of 
enterprises and improve the production efficiency of enterprises by introducing more environmentally friendly equipment or developing cleaner production methods. So what kind of impact green taxation has on business productivity is a question worth studying. Appropriate and reasonable green tax intensity can change a win-win situation for economic development and environmental protection.

Since Solow proposed an analytical framework for total factor productivity (TFP), as an important engine driving industrial growth beyond traditional input factors, TFP can more accurately measure firm productivity [1]. Therefore, this paper will discuss the impact of China's environmental regulation on the TFP of manufacturing.

\subsection{Research Significance}

Environmental protection is a kind of "negative externality" in economics. Environmental pollution is reflected in contemporary negative externalities, and waste of resources is more reflected in intergenerational negative externalities, that is, the waste of resources in the present leads to the exhaustion of resources of future generations. There are two basic ideas for solving negative externalities: one is to follow the Coase Theorem, to define the property rights, to conduct market transactions on the right to environmental pollution; the other is to tax environmental pollution and resource waste according to the concept of Pigou tax. Since the transaction cost in real life cannot be zero, the method of rights trading is costly, and it is particularly important to solve negative externalities through taxation.

According to Pigou's theory, adopting green taxation mediation negative externalities, the benefits arising from the collection of environmental taxes have aroused the research interest of a wide range of scholars, and further put forward the "double dividend" theory: the introduction of environmental taxes can not only effectively inhibit pollution, improve ecology environmental quality, to achieve the goal of environmental protection; and can use its tax revenue to reduce the distortion of the existing tax system on capital and labor, thereby contributing to social employment, sustained economic growth, etc., that is, to achieve "green dividends" and "blue dividends". Since then, some scholars have proved that the environmental tax has an incentive effect on the development of the industry [2]. However, the debate about the "double dividend" still exists. Some scholars believe that environmental tax has uncertainties or even negative effects on industrial performance [3]. Then, in China, the impact of green taxation on the production efficiency of enterprises is worth exploring.

In general, in recent years, with the frequent occurrence of natural disasters and air pollution problems, the government and the public have paid more and more attention to environmental issues. However, because environmental resources have the attributes of public goods, the problem of governance environment cannot be solved by market mechanisms, and it is necessary to rely on government forces for environmental regulation. Considering that a large part of 
China's environmental problems are caused by high energy consumption and high emissions in the manufacturing industry, the manufacturing industry itself has also encountered bottlenecks in resource shortages and is facing enormous pressure to reduce emissions. Therefore, it is very urgent to study how the manufacturing industry can achieve sustainable and healthy development under the dual pressure of energy conservation and emission reduction. In order to test the effect of the government's green tax collection, it is of great practical significance to study the impact of green tax collection on the TFP of the manufacturing industry, improving production efficiency and living environment.

\subsection{Possible Contributions}

This paper systematically summarizes the impact of green tax collection on enterprises and the factors affecting TFP, and further explores whether green tax collection has an impact on corporate TFP. The following innovations may exist:

First, some scholars have reviewed and analyzed the impact of environmental regulation, carbon tax and other factors on the TFP of enterprises. Green taxation has a large advantage in various means of environmental regulation. Therefore, it is meaningful to further analyze whether green taxation has an impact on the TFP of manufacturing enterprises, enriching this research field.

Second, most of the current comprehensive reviews of the relationship between environmental regulation and TFP also focus on the macro level, mainly the impact of environmental regulation of the industry as a whole or the region on the TFP of the industry or region. This paper mainly explores whether the green tax at the enterprise level affects the TFP of enterprises. In the subsequent empirical research, the impact of green taxation on TFP can be explored from the enterprise level, and the shortage of sample size and low degree of freedom can be overcome.

Third, the current literature focuses on the economic benefits of green taxation, and its internal mechanism has not been empirically tested. Since cost and technological innovation are important components that affect TFP, we can empirically analyze the impact mechanism of green taxation on TFP of enterprises from the perspective of technological innovation.

\section{Green Taxation}

\subsection{Definition and Content of Green Taxation}

Green taxation is a concept that emerged from the international taxation academic circles at the end of the 20th century. There is no unified definition so far. Eurostat defines green taxes: taxes that are imposed on the use (or release) of a substance unit that has a specific negative impact on the environment when it is used or released.

The Organization for Economic Cooperation and Development (OECD) divides the environmental tax base into pollution tax, transportation tax, energy tax, and resource tax. The OECD treats land-related taxes as property taxes and 
does not include land-related taxes in the scope of environmental taxes. Based on the income perspective, the taxation degree of China's tax system is estimated to be around $8 \%$ [4]. He did not include environmentally relevant tax revenues in value-added tax and corporate income tax into his green tax revenue. To a certain extent, this underestimates the degree of greening of China's tax system. According to the main policy objectives and functions of green taxation, green taxation is mainly divided into the following three types: cost recovery type, providing incentives and increase income [5]. Mainly used to increase fiscal revenue or green taxes used to reduce other tax distortions. [6] believed that China's new green tax system should be composed of the reformed consumption tax, the newly introduced environmental pollution tax and energy tax, and the "green elements" of other taxes. In China's current tax system, consumption tax, resource tax, and environmental protection tax are the most relevant green taxes related to environmental protection and resource conservation. The establishment of a green tax system based on environmental protection tax, supplemented by consumption tax, resource tax and other taxes containing green elements should be an important part of the green reform of China's tax system.

\subsection{Measurement of Green Taxation}

There is also diversity in the measurement of green taxes in empirical papers. Based on the different adjustment effects of taxation on the resource conservation and environmental protection, three different caliber indicators were constructed to measure the greening degree of China's tax system, namely, small-caliber greening indicators, medium-caliber greening indicators and large-caliber greening indicators [7]. In the concept of China's green tax system, China's future green tax system is divided into dark green, medium green, light green and neutral [8]. Select seven tax types with green adjustment characteristics, specifically consumption tax, resource tax, urban maintenance and construction tax, vehicle purchase tax, vehicle and vessel tax, cultivated land occupation tax, urban land use tax, and the total tax revenue with green taxes and fees, and used the ratio of the sum of sewage charges to measure the level of greening of the tax in the year [9].

\subsection{The Effect of Green Taxation}

In the existing research, the traditional neoclassical economic theory believes that environmental regulation imposes a heavy burden on the economy and is an additional cost imposed by the government. However, some scholars have pointed out that effective environmental regulation will trigger and encourage enterprises to carry out relevant technologies and management innovation, thereby improving the production efficiency and competitive advantage of the enterprise, namely the famous "Porter Theory". [10] hold the concept of "double dividend" and believe that environmental tax reform can not only improve the environment, but also obtain "environmental dividends", optimize the tax 
structure, improve employment levels, promote economic growth, promote social equity, etc., and obtain "non-environmental dividends". However, some scholars believe that although green taxation plays a role in environmental protection, it will inhibit economic development to a certain extent or in the short term. The impact of environmental taxes on China's macro-economy is limited, and the decline of GDP is within the acceptable range. Relatively speaking, the environmental pollution has a much greater effect on the reduction of pollutants than on economic development. The environmental tax at the tax rate can significantly reduce pollutant emissions [11].

\section{Total Factor Productivity}

\subsection{The Concept of Total Factor Productivity}

Productivity is a problem that is often studied in economics, and productivity is one of the important indicators for measuring productivity. Productivity is also an important concept in economic research. It mainly indicates the input-output ratio of various production factors after input, and mainly measures the utilization efficiency of factor inputs. According to previous studies, there are two main types of productivity, as follows: partial factor productivity (PFP), which refers to the utilization efficiency of investing in a production factor, that is, when investing in a production factor; total factor productivity (TFP), which refers to the input-output ratio of other factors after the elimination of capital and labor, or the input-output ratio of production factors of all inputs. The difference is that the range and quantity of input factors calculated are different.

\subsection{Calculation Method of Total Factor Productivity}

Robert Merton Solow (1957) first proposed the Solow residual method. The basic idea is to estimate the TFP, and then use the output growth rate to subtract the residual after the growth rate of each input factor to measure the TFP growth [12]. Under the assumption of constant scale returns and Hicks Neutral technology, TFP growth is equal to the rate of technological progress.

Due to the existence of many defects in the production function method, later generations proposed many econometric methods, in order to accurately estimate TFP by means of various econometric models and measurement tools. For example, the basic idea of the potential output approach is to classify economic growth as three factors: factor input growth, technological progress and capacity improvement (technical efficiency improvement). TFP growth is equal to the sum of technological progress rate and capacity realization rate; estimating the capacity realization rate and the rate of technological progress, the TFP growth rate is given. Later, some scholars introduced the OP method [13], and the LP method [14] and the DEA method [15] were more widely used.

\subsection{Factors Affecting Total Factor Productivity}

At present, there are many researches on factors affecting TFP. This paper 
mainly summarizes the two aspects of enterprises and systems. The main influencing factors are as follows:

Market factors. Trade liberalization can directly enhance TFP by correcting factor market distortions and eliminating trade barriers [16]. Resource misplacement can inhibit productivity growth, and expanding local market size and improving resource allocation efficiency can significantly increase the TFP [17].

Structural factors. Productivity changes are closely related to the manufacturing industry structure, because changes in the manufacturing industry structure will produce "structural dividends", which will promote the growth of TFP and sustainable economic development. However, this promotion effect is only obvious in the early stage of industrial structure changes. And then it will continue to weaken. [18] considered that the growth rate of TFP of capital-intensive manufacturing is lower than that of labor-intensive manufacturing and extractive industries. The proportion of Chinese enterprises is negatively correlated with TFP, while improving the market competition of the industry is helpful.

Foreign direct investment, referred to as FDI. FDI can generate technology spillovers to improve corporate TFP. FDI has the greatest impact on state-owned enterprises, while private and foreign-funded enterprises can benefit from FDI, while high-tech enterprises are also beneficiaries [19].

Research and development, referred to as R \& D. R \& D can influence the TFP of enterprises through technology spillovers generated by international trade channels and domestic R \& D inputs [20].

Environmental regulation. [21] considered that the relationship between environmental regulation and enterprise TFP is consistent with the "inverted N-type" relationship, that is, when the intensity of environmental regulation is weak, the environmental cost of the enterprise is low, the motivation for technological innovation is insufficient, and the factor productivity is reduced; when environmental regulation is improved When the technological innovation can be promoted, as long as the environmental regulation is within a reasonable range, the TFP of the enterprise will be promoted; but when the environmental regulation intensity exceeds the burden that the enterprise can bear, the TFP will decrease.

\section{The Impact of Green Taxation on Corporate Total Factor Productivity}

According to Porter's Theory, from the perspective of innovation compensation effect, the indirect impact of green taxation on total factor productivity of enterprises is mainly implemented by affecting the allocation of resources in the process of technological innovation of enterprises and thus changing the plan of technological innovation of enterprises. Porter's Theory pointed out that in order to control the pollution generated in the production process of the enterprise, the government must formulate relevant environmental regulation policies to limit the production of enterprises. If the government's environmental protection policy is appropriate, within the scope that most companies can tolerate, 
it will not hinder the improvement of enterprise productivity, but will stimulate enterprises to carry out technological innovation to improve the total factor productivity of enterprises; but the intensity of regulation exceeds one degree. After that, it will hinder the improvement of the company's production efficiency.

The purpose of the government's environmental regulation policy is to improve the ecological environment, reduce pollution generated during the production process, and rationalize the use of resources. The strategic management of an enterprise must be carried out under economic and environmentally sustainable conditions. It must improve the production process, technology and raw materials of the enterprise, and use more environmentally friendly production processes and environmentally friendly materials for production, thereby reducing the environmental regulation of enterprises. The cost of the aspect increases the total factor productivity of the enterprise. Furthermore, under the condition that environmental problems continue to heat up, the public's awareness of environmental protection is gradually increasing, and the needs of consumers are beginning to change. Consumers are more inclined to green production products, and market demands will also promote technology research and development. From this process, it can also promote technological innovation of enterprises.

In summary, green taxation can promote corporate TFP improvement through the following aspects. First, the levy of green taxation can encourage enterprises to use resources, allocate resources reasonably, and promote enterprises to improve resource utilization efficiency. Second, the implementation of environmental protection policies will enhance the public's awareness of environmental protection and preferences for clean products. Environmental regulation policies can encourage enterprises to develop cleaner products and reduce pollutant emissions, thus establishing a good corporate image in front of the public. The company's total factor productivity and corporate competitiveness have a positive impact.

\section{Policy Recommendations}

First, set a reasonable green tax intensity. Reasonable collection of green taxes can encourage enterprises to save resources, allocate resources reasonably, and promote enterprises to improve the efficiency of resource utilization. At the same time, the collection of green taxes can encourage enterprises to develop cleaner products and reduce pollutant emissions, so as to establish a good corporate image of the company in the face of the public, improve the reputation of the company and demonstrate corporate social responsibility, the TFP of enterprises and enterprises. Competitiveness has a positive impact. But also remember to blindly improve China's green taxation level, should consider the actual green tax affordability of most companies.

Second, develop differentiated industry green tax intensity and set different green tax intensity for different industries. Studies have shown that there is a 
difference in the relationship between green tax intensity and TFP in the general industry and heavily polluting industries. For the heavily polluting industries, a more stringent green tax policy should be formulated to achieve environmental protection and TFP improvement..

Third, a flexible form of green taxation is necessary. The impact of green taxation on TFP depends not only on the intensity of green taxation, but also on the specific form of green taxation. More reasonable green taxation tools will reduce the cost effect of green taxation on enterprises and reduce green taxation.

\section{Conclusions}

According to the previous article, we find that the following defects may exist in literature. Firstly, the impact on the TFP of enterprises is more from the perspective of environmental regulation, and there is no specific analysis of the impact of green taxation on TFP. Secondly, due to the inconsistency of research perspectives, research methods, and conceptual definitions, there is no consensus on current research on the impact of environmental regulation on TFP, and the conclusions are not consistent. Thirdly, most of the papers focus on the macro level to research the relationship between environmental regulation and TFP also focuses on. The research of pre-scientists is mainly the impact of environmental regulation of the industry as a whole or the whole region on the TFP of the industry or region. Using regional or industry samples, there are problems such as small sample size and low degree of freedom.

China's current environmental pollution problem is serious, and the main pollution comes from the pollution of industrial enterprises. How to limit the sewage discharge of enterprises, reduce the cost of environmental governance, and improve the ecological environment has become an urgent problem to be solved. Therefore, the government has adopted a series of environmental regulation measures, such as the January 1st, 2018, "The Environmental Protection Tax Law of the People's Republic of China" was officially implemented. The impact of green tax collection on business productivity is a question worth studying.

\section{Conflicts of Interest}

The author declares no conflicts of interest regarding the publication of this paper.

\section{References}

[1] Jefferson, G.H., Rawski, T.G. and Zhang, Y. (2008) Productivity Growth and Convergence across China's Industrial Economy. Journal of Chinese Economic and Business Studies, 6, 121-140. https://doi.org/10.1080/14765280802028237

[2] Cheng, Z., Wei, L., Lu, G., et al. (2011) Environmental Regulation Strength and Production Technology Progress. Economic Research, 2, 113-124.

[3] Fu, J.Y., Hu, W. and Cao, X. (2018) FDI, Environmental Regulation and Green Total Factor Productivity from Different Sources. International Trade Issues, 7, 45-58.

[4] Rao, L.X. (2008) Analysis of the Policy and Income of the Current Tax System "Greening". Tax Research, 5, 60-62. 
[5] Han, C. and Wang, G.M. (2011) Analysis of the Green Degree of Taxation in China. Inner Mongolia Science and Technology and Economy, 6, 47-75.

[6] Ge, Y.Y. (2016) “Greening” China's Tax System with the Concept of Green Development. Taxation Research, 10, 8-13.

[7] Deng, X.L. and Wang, Y.J. (2013) Study on the Greening Degree of China's Tax System-Based on the Measurement of Three Statistical Caliber Indicators of Large, Medium and Small. Audit and Economic Research, 6, 71-79.

[8] Su, Z. (2015) Thoughts on Building China's Green Tax System. Economic Research Reference, 41, 50-53.

[9] Ping, G. and Meng, G. (2017) Research on the Impact of Green Taxation on Green Transformation of Manufacturing Industry. Eco-Economy, 33,133-137.

[10] Wang, X.B., Pan, E.Y. and Ma, D.C. (2014) Existence of China's Environmental Tax "Double Dividend". Ecology and Economy, 7, 37-42.

[11] Qin, C.B., Wang, J.N., Ge, C.Z., Gao, S.T. and Liu, Q.Q. (2015) Impact of Environmental Tax on Economic and Pollution Emissions. China Population, Resources and Environment, 1, 17-23.

[12] Pillow, S. (1988) How to Understand and Calculate the Growth of "All-Factor Productivity"-A Quantitative Analysis of a Specific Technical and Economic Problem. Quantitative Economics and Technology Economics Research, 12, 68-71.

[13] Olley, S. and Pakes, A. (1996) The Dynamics of Productivity in the Telecommunications Equipment Industries. Econometrica, 64, 1263-1298. https://doi.org/10.2307/2171831

[14] Levinsohn, J. and Petrin, A. (2003) Estimating Production Functions Using Inputs to Control for Unobservabless. Review of Economic Studies, 2, 317-341. https://doi.org/10.1111/1467-937X.00246

[15] Bernini, C., Cerqua, A. and Pellegrini, G. (2017) Public Subsidies, TFP and Efficiency: A Tale of Complex Relationships. Research Policy, 46, 751-767. https://doi.org/10.1016/j.respol.2017.02.001

[16] Mao, Q.L. (2013) Factor Market Distortion and China's Industrial Enterprise Productivity: An Analysis Based on the Perspective of Trade Liberalization. Financial Research, 2, 156-169.

[17] Huang, D.D. and Fu, J.P. (2015) Estimation of Total Factor Productivity of Photovoltaic Enterprises and Analysis of Influencing Factors (1996-2011). Science and Technology Management Research, 13, 81-89.

[18] Feng, M. and Wang, Q.H. (2013) What Influences the Change of Productivity Structure in the Manufacturing Industry?-An Empirical Study Based on Data of Chinese Industrial Enterprises from 1998 to 2007. Industrial Economics Research, 3, 35-44.

[19] Wu, Y., Song, Y. and Deng, G. (2017) Institutional Environment, OFDI, and TFP Growth: Evidence from China. Emerging Markets Finance \& Trade, 53, 2020-2038. https://doi.org/10.1080/1540496X.2017.1283612

[20] Wang, Y.C. (2017) Analysis of Total Factor Productivity and Its Influencing Factors in China's Advanced Equipment Manufacturing Industry-Based on the Perspective of Industrial Organization. Industrial Technology \& Economy, 1, 15-21.

[21] Wang, J. and Liu, B. (2014) Environmental Regulation and Enterprise Total Factor Productivity-An Empirical Analysis Based on Data of Chinese Industrial Enterprises. China Industrial Economy, 3, 44-56. 